\title{
Photodegradation of Eosin Y Using Silver-Doped Magnetic Nanoparticles
}

\author{
Eman Alzahrani \\ Chemistry Department, Faculty of Science, Taif University, P.O. Box 888, Taif, Saudi Arabia \\ Correspondence should be addressed to Eman Alzahrani; em-s-z@hotmail.com
}

Received 21 August 2015; Accepted 8 October 2015

Academic Editor: Lawrence A. Bottomley

Copyright ( 2015 Eman Alzahrani. This is an open access article distributed under the Creative Commons Attribution License, which permits unrestricted use, distribution, and reproduction in any medium, provided the original work is properly cited.

\begin{abstract}
The purification of industrial wastewater from dyes is becoming increasingly important since they are toxic or carcinogenic to human beings. Nanomaterials have been receiving significant attention due to their unique physical and chemical properties compared with their larger-size counterparts. The aim of the present investigation was to fabricate magnetic nanoparticles (MNPs) using a coprecipitation method, followed by coating with silver $(\mathrm{Ag})$ in order to enhance the photocatalytic activity of the MNPs by loading metal onto them. The fabricated magnetic nanoparticles coated with Ag were characterised using different instruments such as a scanning electron microscope (SEM), transmission electron microscopy (TEM), energy-dispersive X-ray (EDAX) spectroscopy, and X-ray diffraction (XRD) analysis. The average size of the magnetic nanoparticles had a mean diameter of about $48 \mathrm{~nm}$, and the average particle size changed to $55 \mathrm{~nm}$ after doping. The fabricated Ag-doped magnetic nanoparticles were used for the degradation of eosin Y under UV-lamp irradiation. The experimental results revealed that the use of fabricated magnetic nanoparticles coated with Ag can be considered as reliable methods for the removal of eosin Y since the slope of evaluation of pseudo-first-order rate constant from the slope of the plot between $\ln \left(C_{o} / C\right)$ and the irradiation time was found to be linear. Ag-Fe $\mathrm{O}_{4}$ nanoparticles would be considered an efficient photocatalyst to degrade textile dyes avoiding the tedious filtration step.
\end{abstract}

\section{Introduction}

In recent decades, environmental problems have attracted increasing attention all over the world. One type of environmental pollutants of concern is synthetic dyes, which are commonly used for colouring materials such as textiles, leather, paper, wool, printed matter, and cosmetics $[1,2]$. Although the exact number of the produced dyes in the world is not known, it is estimated that there are more than 100,000 different available dyes. These dyes are difficult to decolourise because of their complex aromatic structure, which originates from coal-tar-based hydrocarbons such as benzene, naphthalene, anthracene, toluene, and xylene [3-8]. Commonly, these dyes are discharged into the environment in the form of coloured wastewater by many industries without any prior treatment; however, many of them are known to be toxic or carcinogenic to human beings [9-11]. Therefore, several researchers are working on methods for the removal of dyes from wastewater before their discharge into downstream bodies of water [12-16].
There are several methods that have been utilised for the removal of dyes from industrial wastewater, for example, adsorption, nanofiltration, ozonation, and electroflotation [17-19]. All of these processes have different capabilities for removing dyes. Among these methods, adsorption has been found to be the best technique for wastewater purification [20-22], due to the simplicity of the procedure, ease of operation, and its nonsensitivity to toxic substances. The purification of wastewater from harmful dyes can be performed using activated carbon, which has a high surface area [23-26]; however, it also has a high waste cost. Other materials that can be utilised are alum, ferric salt, or lime. Although the cost of these materials is cheap, they suffer from several severe drawbacks [27-30].

The field of nanotechnology is one of the most active areas of research in modern materials science. The application of nanoscale materials, which range from 1 to $100 \mathrm{~nm}$, is a key emerging area of nanotechnology. There is an increased demand for nanoparticles because of their wide applicability 
in various areas, for example, electronics, catalysis, chemistry, energy, and medicine [31-34].

Magnetic nanoparticles (MNPs) are a type of nanoparticles that can be manipulated using a magnetic field. MNPs are attracting significant attention due to their large surface area, high magnetic properties, high thermal stability, high mechanical strength, and lack of toxicity [35-37]. Moreover, MNPs can be rapidly prepared, have high separation efficiency, are cost-effective, and provide for a simple operational process. They are utilised in applications such as magnetic drug targeting, magnetic resonance imaging for clinical diagnosis, recording material, and biomedical applications [38-41].

MNPs possessing magnetite $\left(\mathrm{Fe}_{3} \mathrm{O}_{4}\right)$ or maghemite $(\gamma$ $\mathrm{Fe}_{2} \mathrm{O}_{3}$ ) core chemistry have been used to solve a range of environmental problems; for example, MNPs have been utilised for the purification of wastewater by removing heavy metals, alkalinity, and hardness, as well as natural organic compounds and salt. This is due to their simple fabrication, easy optimisation of their size and morphology, and fast magnetic separation under an external magnetic field [4245].

Iron oxide nanoparticles can be fabricated using different methods, for example, coprecipitation, energy milling, reduction, and ultrasonic-assisted impregnation. The coprecipitation method is based on mixing ferrous and ferric ions in the ratio of 1 to 2 in an alkaline medium. The main advantage of this method is that it produces fine and stoichiometric particles of single and multicomponent metal oxides [46-50].

In order to improve the physicochemical properties of MNPs and to achieve different kinds of applications, modification of the surfaces of MNPs with functional groups is necessary [51, 52]. The doping of MNPs with metals can resolve the problem of the fast recombination of charge carriers, which happens within nanoseconds, by trapping and subsequently transferring the photoexcited electrons onto the surface of photocatalyst, resulting in decreased recombination of the electron-hole pairs $[53,54]$.

According to our literature survey, only very few studies have been carried out on the use of MNPs doping with metal for the photodegradation of harmful dyes. Therefore, the purpose of the present paper is to describe the fabrication of magnetic nanoparticles (MNPs) using the precipitation method, followed by doping of the MNPs with Ag. Characterisations of the fabricated Ag-doped magnetic nanoparticles were performed by studying the physical properties of the fabricated nanoparticles using scanning electron microscopy (SEM) analysis, transmission electron microscopy (TEM) analysis, energy-dispersive $\mathrm{X}$-ray analysis (EDAX), and X-ray diffraction (XRD) analysis. The fabricated materials were used for the photodegradation of a model dye, namely, eosin $\mathrm{Y}$ (the characteristics of eosin $\mathrm{Y}$ are given in Table 1), in the presence of ultraviolet light (UV). Furthermore, the photocatalytic activity of the Ag-MNPs was compared with naked MNPs. Moreover, the degradation kinetics were followed to study the photocatalytic efficiency of the Ag-MNPs.
TABLE 1: The characteristics of eosin Y dye.

\begin{tabular}{lc}
\hline Chemical name & $\begin{array}{c}\text { 2-(2,4,5,7-Tetrabromo-6-oxido-3-oxo-3 } \mathrm{H} \text { - } \\
\text { xanthen-9-yl)benzoate }\end{array}$ \\
\hline Chemical formula & Anionic dye \\
\hline Chemical structure & $515 \mathrm{~nm}^{-1}$ \\
\hline Molecular weight & $647.89 \mathrm{~g} \mathrm{~mol}^{-1}$ \\
\hline$\lambda_{\text {max }}$ of dye & BOH
\end{tabular}

\section{Experimental}

2.1. Chemicals and Materials. Iron(II) sulfate heptahydrate $\left(\mathrm{FeSO}_{4} \cdot 7 \mathrm{H}_{2} \mathrm{O}, 98 \%\right)$, Mwt. $=151.91 \mathrm{~g} \mathrm{~mol}^{-1}$, sodium nitrite $\left(\mathrm{NaNO}_{3}, 99 \%\right)$, and eosin $\mathrm{Y}$ were purchased from SigmaAldrich (Nottingham, UK). Sodium hydroxide $(\mathrm{NaOH})$ was purchased from Loba Chemie Pvt. Ltd. (Mumbai, India). Silver nitrate $\left(\mathrm{AgNO}_{3}, 99.85 \%\right)$ and sodium carbonate $\left(\mathrm{Na}_{2} \mathrm{CO}_{3}\right)$ were purchased from Acros Organics (Loughborough, UK). Cylindrical rod magnets $(40 \mathrm{~mm}$ diameter $\times$ $40 \mathrm{~mm}$ thickness) for settlement of the magnetic nanoparticles were purchased from Magnet Expert Ltd. (Tuxford, UK). Distilled water was employed for preparing all the solutions and reagents.

2.2. Instrumentation. The magnetic stirrer and heater were purchased from Fisher Scientific Co. Ltd. (Shanghai, China). The oven was from Memmert (Nuremberg, Germany). Xray diffraction (XRD) patterns were obtained using a Bruker diffractometer D8-ADVANCE with $\mathrm{CuK}_{\alpha 1}$ radiation (Coventry, UK). The transmission electron microscope (TEM) came from JEOL Ltd. (Welwyn Garden City, UK). The scanning electron microscope (SEM) with unit energy-dispersive Xray analysis (EDAX) was obtained from JEOL JSM 6390 LA Analytical (Tokyo, Japan). The UV lamp $(\lambda=365 \mathrm{~nm})$ was purchased from Spectronic Analytical Instruments (Leeds, UK). The UV-Vis spectrophotometer was from Thermo Scientific GENESYS 10S (Toronto, Canada).

\subsection{Preparation of the Magnetic Iron Oxide Nanoparticles.} Magnetic nanoparticles (MNPs) were prepared as described by Tan and Bakar [55], with some modification. MNPs were obtained by dissolving $3.3 \mathrm{~g}$ of $\mathrm{FeSO}_{4} \cdot 7 \mathrm{H}_{2} \mathrm{O}$ and $2 \mathrm{~g}$ of $\mathrm{NaNO}_{3}$ in $50 \mathrm{~mL}$ of distilled water. Then, $20 \mathrm{~mL}$ of $\mathrm{NaOH}$ solution $(2.5 \mathrm{M})$ was added to the mixture while it was heated up to $80^{\circ} \mathrm{C}$. The reaction was allowed to proceed at $80^{\circ} \mathrm{C}$ under constant stirring to ensure the complete growth of the nanoparticle crystals. After 30 minutes, the resulting suspension was cooled down to room temperature and washed with distilled water repeatedly to remove unreacted chemicals. The $\mathrm{Fe}_{3} \mathrm{O}_{4}$ magnetic nanoparticles were separated 
using an external magnet and dried in an oven at $50^{\circ} \mathrm{C}$ overnight before the coating.

2.4. Doping of MNPs with Ag. The prepared magnetic nanoparticles were doped with Ag. This was performed by mixing $10 \mathrm{~g}$ of magnetic nanoparticles with $10 \mathrm{~mL}$ of silver nitrate solution $(0.1 \mathrm{M})$. Then, $10 \mathrm{~mL}$ of sodium carbonate (1\%) solution was added. The suspension was dried at $80^{\circ} \mathrm{C}$ for $24 \mathrm{~h}$, and finally the formed powder was calcinated at $400^{\circ} \mathrm{C}$ for $6 \mathrm{~h}$ in a furnace. The formed $\mathrm{Ag}$-doped MNPs were washed with distilled water. The product was dried at room temperature for $12 \mathrm{~h}$ in a vacuum desiccator.

2.5. Characterisation of the Prepared Materials. The morphology and mean size of the samples were determined by transmission electron microscopy (TEM). A drop of welldispersed nanoparticle dispersion was placed onto the amorphous carbon-coated 200-mesh copper grid and allowed to dry at ambient temperature, and then the grid was scanned. The average size of about 100 nanoparticles of each sample was measured from the TEM images by using the ImageJ software. The morphology of the fabricated magnetic nanoparticles before and after doping with Ag was characterised by SEM analysis. The compositional analysis was performed using energy-dispersive X-ray analysis (EDAX). Phase identification and structural analysis of the magnetic nanoparticles were carried out using X-ray diffraction (XRD) with the $\mathrm{CuK}_{\alpha}$ radiation in the 2-theta range from $20^{\circ}$ to $70^{\circ}$.

2.6. Photocatalytic Degradation of Eosin $Y$. The photocatalytic activity of $\mathrm{Ag}$-doped $\mathrm{Fe}_{3} \mathrm{O}_{4}$ nanoparticles was investigated by the decolourisation of eosin $\mathrm{Y}$ in aqueous solution. All the degradation reactions were performed according to the following procedure: $50 \mathrm{mg}$ of photocatalyst was added to $100 \mathrm{~mL}$ of aqueous dye solution $\left(4 \times 10^{-4} \mathrm{M}\right)$ placed in a cylindrical glass vessel. Before exposure to the UV lamp, the suspension was magnetically stirred at $600 \mathrm{rpm}$ for $1 \mathrm{~h}$ in the dark in order to achieve the adsorption-desorption equilibrium between the photocatalyst and the dye. The reaction was performed with constant magnetic stirring during the reaction. A $2 \mathrm{~mL}$ aliquot was withdrawn from the mixture solution at $60 \mathrm{~min}$ intervals. The degradation of eosin Y was spectrometrically monitored with a UV-Vis spectrophotometer at a wavelength between 350 and $800 \mathrm{~nm}$ according to the dye. The photocatalyst was precipitated from the solution by applying an external magnet and then washed with distilled water and stored for further use. The efficiency of the photocatalytic degradation of the fabricated materials was calculated based on the degree of absorption in the absorption spectra of the dye solution with respect to the intensity corresponding to $\lambda_{\max }$ of eosin Y (515 nm) by using the equation given below [56-58]:

$$
D \%=\frac{C_{o}-C}{C_{o}} \times 100=\frac{A_{o}-A}{A_{o}} \times 100,
$$

where $C_{o}$ is the initial concentration of the dye and $C$ is the concentration of the dye after irradiation in a selected time interval. Parameters $A_{o}$ and $A$ are the absorbance of eosin Y solutions in the $515 \mathrm{~nm}$ wavelength at the initial and at any time thereafter, respectively.

\section{Results and Discussion}

3.1. Preparation of $\mathrm{Fe}_{3} \mathrm{O}_{4}$ and the $\mathrm{Ag}$-Doped $\mathrm{Fe}_{3} \mathrm{O}_{4}$ Nanoparticles. In this study, magnetic nanoparticles (MNPs) were fabricated. The reason for choosing this type of nanoparticle was because it is easy to fabricate and it is easy to separate it from the solution by using an external magnet $[38,59,60]$. The chemical precipitation technique was used to prepare the magnetic nanoparticles. This technique is probably the most common and efficient method to obtain magnetic particles [40, 61, 62]. The fabrication of MNPs was performed by mixing iron(II) sulfate heptahydrate and sodium nitrite in purified water. Complete precipitation of $\mathrm{Fe}_{3} \mathrm{O}_{4}$ nanoparticles was achieved under alkaline condition, which was $20 \mathrm{~mL}$ of $\mathrm{NaOH}$ solution $(2.5 \mathrm{M})$. When $\mathrm{NaOH}$ solution was added to the $\mathrm{FeSO}_{4}, \mathrm{Fe}(\mathrm{OH})_{2}$ was initially formed, which was then oxidised to the $\mathrm{Fe}_{3} \mathrm{O}_{4}$ nanoparticle $[61,63,64]$. Finally, the formed magnetic nanoparticles were separated from the reaction medium by a permanent magnet field and washed with distilled water to remove excess ions such as $\mathrm{SO}_{4}{ }^{2-}$ and $\mathrm{NO}_{3}{ }^{-}$.

The MNPs were doped with Ag in order to obtain a higher photocatalytic efficiency than the naked $\mathrm{Fe}_{3} \mathrm{O}_{4}$ nanoparticles. After calcination, the colour of the $\mathrm{Fe}_{3} \mathrm{O}_{4}$ nanoparticles turned from black to brownish. Figure 1 shows photographs of aqueous solutions of the unsupported $\mathrm{Fe}_{3} \mathrm{O}_{4}$ nanoparticles (a) and $\mathrm{Ag}$-doped $\mathrm{Fe}_{3} \mathrm{O}_{4}$ nanoparticles (b) in vials before and after magnetic separation using an external magnetic field, while Figure 1(c) shows the dried fabricated materials.

3.2. Characterisation of the Fabricated Materials. The catalytic power of the photocatalysts is affected by the size of the nanoparticles, the distribution of the sizes, and the morphology, since the size of nanoparticles has a strong effect on the energy levels of the photocatalysts [65-67]. Therefore, to obtain a good understanding of the photocatalytic processes, the size of the particles and the morphology should be studied. The fabricated materials were thus characterised using different techniques, namely, TEM analysis and SEM analysis. In addition, compositional analysis was performed using energy-dispersive X-ray analysis (EDAX). For phase identification and the structural analysis of the magnetic nanoparticles, an X-ray diffraction (XRD) instrument was utilised.

3.2.1. TEM Analysis. A transmission electron microscope is a good tool for extraction of the size and shape data because it yields real images from which measurements can be made $[34,68,69]$; therefore, this was used in order to recognise the morphology and the size of the prepared materials. Figure 2 shows TEM micrographs of the unsupported $\mathrm{Fe}_{3} \mathrm{O}_{4}$ nanoparticles and the Ag-doped $\mathrm{Fe}_{3} \mathrm{O}_{4}$ nanoparticles using different magnifications. Although the fabricated magnetic nanoparticles were crystalline and tended to have identifiable shapes (rectangles and squares), there were some differences in the comparison. The TEM images showed that the 


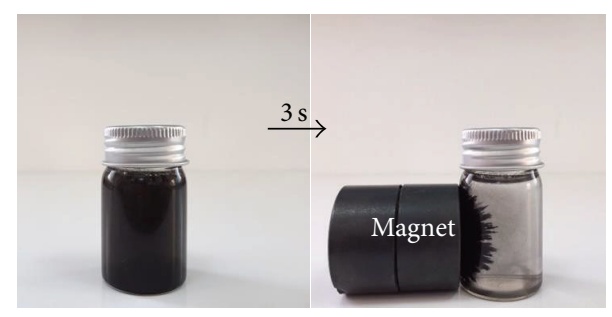

(a)

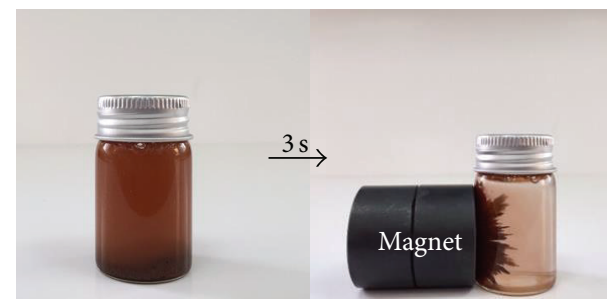

(b)

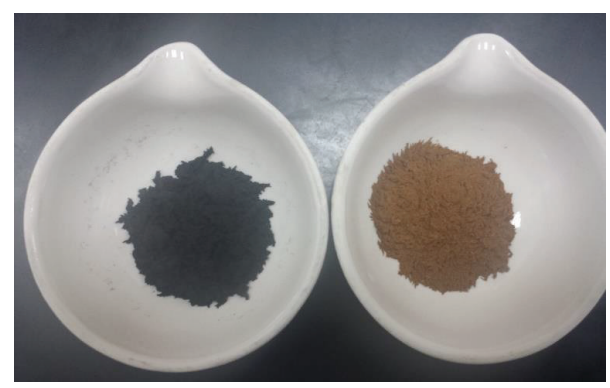

(c)

FIgURE 1: Photographs of aqueous solutions of $\mathrm{F}_{3} \mathrm{O}_{4}$ nanoparticles (a), $\mathrm{Ag}-\mathrm{Fe}_{3} \mathrm{O}_{4}$ nanoparticles in a vial (b) before and after being separated from solution using an external magnet for $3 \mathrm{~s}$, and (c) the dried fabricated materials.

magnetic nanoparticles appeared darker after coating with $\mathrm{Ag}$ and they seemed more compact compared with $\mathrm{Fe}_{3} \mathrm{O}_{4}$ nanoparticles, indicating that $\mathrm{Ag}$-doped $\mathrm{Fe}_{3} \mathrm{O}_{4}$ nanoparticles had a higher density than that of $\mathrm{Fe}_{3} \mathrm{O}_{4}$ nanoparticles. The particle size distribution histograms for MNPs and Ag-MNPs have been determined from TEM images (Figure 2), and the corresponding size distribution histograms are shown in Figure 3. The average size of the MNPs was $48 \mathrm{~nm}$ within size ranging from 24 to $60 \mathrm{~nm}$. The size distribution of $\mathrm{Ag}$ MNPs ranged from $30 \mathrm{~nm}$ to $62 \mathrm{~nm}$, within average size of $55 \mathrm{~nm}$. Commonly, the average diameter of coating MNPs will increase in the range of $0-5 \mathrm{~nm}$ compared with the naked MNPs [51]. It was found that the TEM analysis served as an important technique for providing evidence of the formation of the Ag-doped $\mathrm{Fe}_{3} \mathrm{O}_{4}$ nanoparticles.

3.2.2. SEM-EDAX Analysis. The morphology and structures of the $\mathrm{Fe}_{3} \mathrm{O}_{4}$ nanoparticles and the $\mathrm{Ag}$-doped $\mathrm{Fe}_{3} \mathrm{O}_{4}$ nanoparticles were also investigated by SEM analysis. Figure 4 shows the SEM micrographs of the $\mathrm{Fe}_{3} \mathrm{O}_{4}$ nanoparticles and the Ag-doped $\mathrm{Fe}_{3} \mathrm{O}_{4}$ nanoparticles in different magnifications, which suggest that the prepared magnetic nanoparticles have an irregular crystalline form, and furthermore, the surface morphology analysis demonstrates the agglomeration of many ultrafine particles. In addition, no significant morphological differences could be observed between the $\mathrm{Fe}_{3} \mathrm{O}_{4}$ nanoparticles and the Ag-doped $\mathrm{Fe}_{3} \mathrm{O}_{4}$ nanoparticles.

In order to further identify the chemical composition of the fabricated materials, EDAX was utilised to recognise the distribution of $\mathrm{Fe}, \mathrm{O}$, and $\mathrm{Ag}$ atoms in the prepared materials. The characterisations of the fabricated $\mathrm{Fe}_{3} \mathrm{O}_{4}$ nanoparticles and $\mathrm{Ag}$-doped $\mathrm{Fe}_{3} \mathrm{O}_{4}$ nanoparticles using EDAX are shown in Figure 5. The EDAX spectra showed strong peaks of $\mathrm{Fe}$ and $\mathrm{O}$. It was observed that there was a new peak in the Ag-doped $\mathrm{Fe}_{3} \mathrm{O}_{4}$ sample, representing Ag, which confirms the doping of the magnetic nanoparticles with silver.

3.2.3. XRD Analysis. The obtained samples were analysed by $\mathrm{X}$-ray diffraction (XRD) using a diffractometer with highintensity $\mathrm{CuK}_{\alpha}$ radiation $(\lambda=1.54065 \AA)$ and measured from $10^{\circ}$ to $70^{\circ}$, and the results are depicted in Figure 6. For the $\mathrm{Fe}_{3} \mathrm{O}_{4}$ diffraction peaks, seven characteristic peaks at $30^{\circ}$, $35^{\circ}, 37^{\circ}, 43^{\circ}, 53^{\circ}, 57^{\circ}$, and $62^{\circ}$ were seen, corresponding to the (220), (311), (222), (400), (422), (511), and (440) crystal planes of pure $\mathrm{Fe}_{3} \mathrm{O}_{4}$ with a cubic spinel structure of the magnetite $[63,70,71]$. No characteristic peaks of impurities were detected in the XRD pattern, indicating the high purity of fabricated materials. The XRD patterns of Ag-doped $\mathrm{Fe}_{3} \mathrm{O}_{4}$ did not show diffraction peaks due to the doping of $\mathrm{Ag}$, since there was no peak of Ag observed; therefore, it is suggested that the silver dopant was merely placed on the surface of the crystals. The same results have been obtained by [72].

\subsection{Photodegradation of Eosin $Y$}

3.3.1. Comparison between the Naked MNPs and the Ag-MNPs Nanoparticles. An organic dye, namely, eosin Y, in aqueous solution was utilised in order to check the performance of the fabricated materials, and their performance was compared with naked magnetic nanoparticles. The photodegradation experiment was performed by adding $50 \mathrm{mg}$ of catalyst to $100 \mathrm{~mL}$ of the dye solution $\left(4 \times 10^{-4} \mathrm{M}\right)$. The suspension was magnetically stirred at $600 \mathrm{rpm}$ in the dark for $1 \mathrm{~h}$ in order to attain adsorption-desorption equilibrium before the irradiation by UV light $(365 \mathrm{~nm})$. The main advantage of using the UV light was to produce electron and hole pair $\left(\mathrm{e}^{-} / \mathrm{h}^{+}\right)$with high energy state that migrate to the nanoparticle surface and initiate a wide range of chemical reactions [73].

The suspension was magnetically stirred throughout the experiment. For different irradiation times $(0-240 \mathrm{~min})$, at every $60 \mathrm{~min}$ interval, an aliquot $(2 \mathrm{~mL})$ was taken out. It was observed that the intense orange colour of the initial solution disappears gradually and becomes colourless as the irradiation time increases, indicating the degradation of the dye under UV light irradiation, as can be seen in Figure 7.

The absorption spectra of the dye solution were recorded, as shown in Figure 8, which shows the UV-Vis timedependent absorption spectrum during the photocatalytic reaction of eosin Y. From the figure, it can be seen that the absorption spectrum maximum of eosin $Y$ steadily decreases 


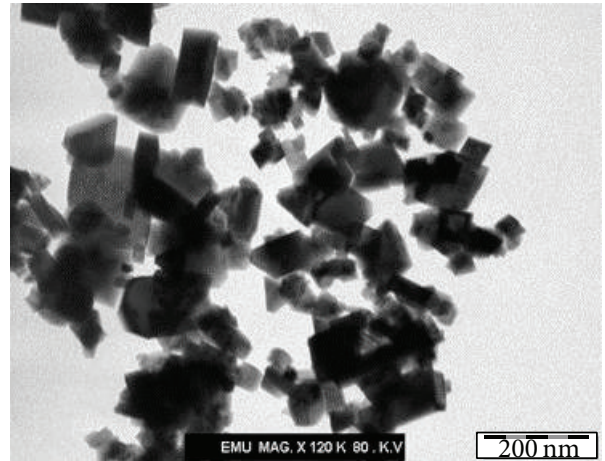

(a)

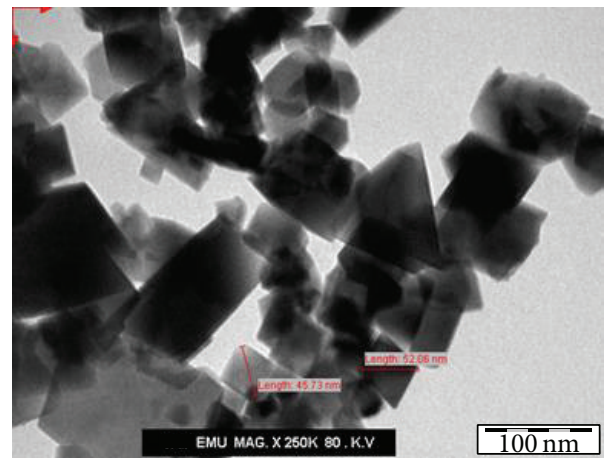

(c)

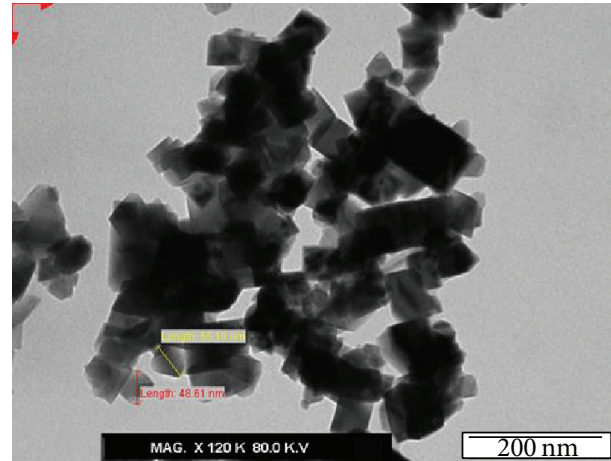

(b)

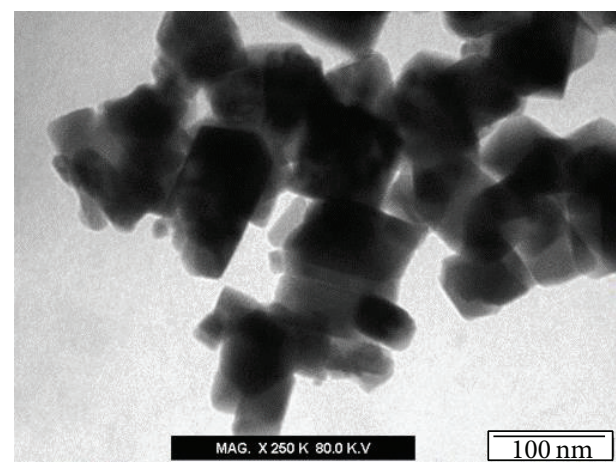

(d)

Figure 2: TEM micrographs of naked $\mathrm{Fe}_{3} \mathrm{O}_{4}$ nanoparticles ((a), (c)) and Ag-doped $\mathrm{Fe}_{3} \mathrm{O}_{4}$ nanoparticles ((b), (d)) at different magnifications.
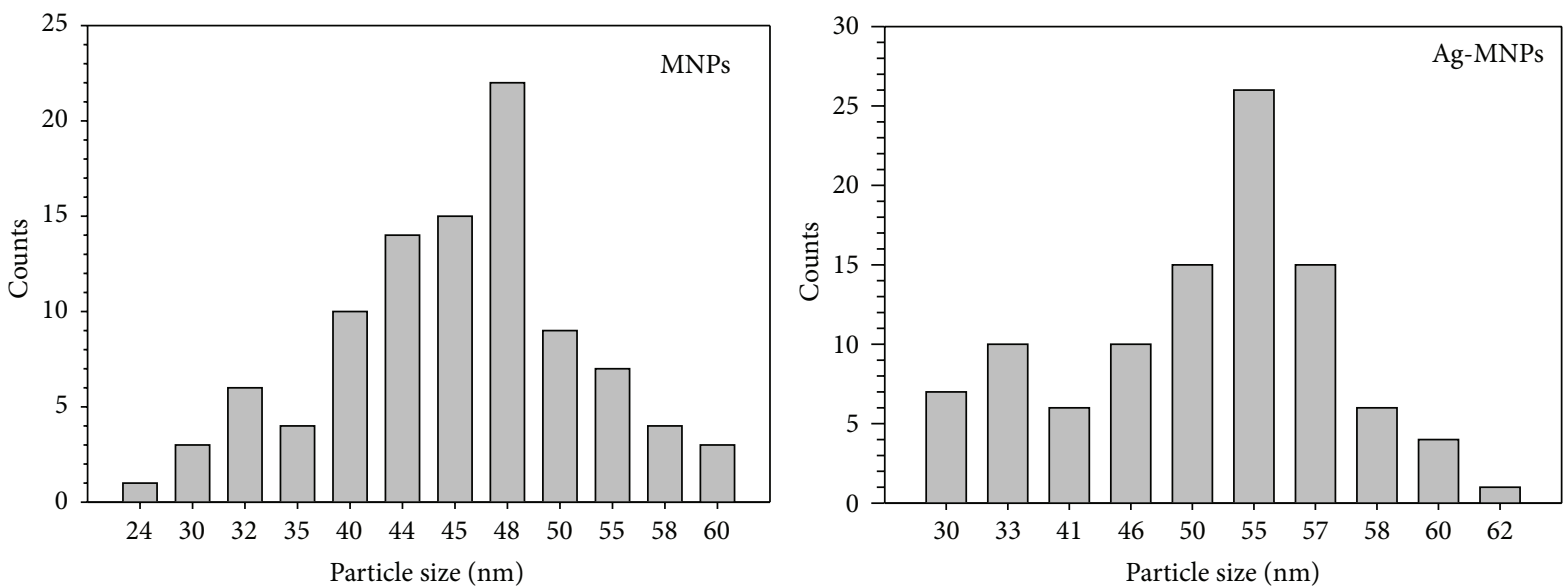

Figure 3: The size distribution histograms of MNPs and Ag-MNPs corresponding to TEM images (a)-(d) shown in Figure 2. The size distribution was obtained by counting 100 nanoparticles for each sample.

as the exposure time of UV light increases from 0 to $240 \mathrm{~min}$, indicating the process of photodecomposition of the dye.

The photocatalytic activities of the naked $\mathrm{Fe}_{3} \mathrm{O}_{4}$ nanoparticles and a solution without the photocatalyst, for comparison, were also investigated. It was found that, without adding the photocatalyst, the degradation of eosin $\mathrm{Y}$ was very slow at only $5 \%$, while the naked $\mathrm{Fe}_{3} \mathrm{O}_{4}$ nanoparticles showed lower photocatalytic degradation of $40 \%$. The colour removal process of eosin $\mathrm{Y}$ using $\mathrm{Ag}-\mathrm{Fe}_{3} \mathrm{O}_{4}$ nanoparticles was significantly higher, reaching almost $90.12 \%$ decolourisation.
Figure 9 shows the plot of $C / C_{o}$ versus irradiation time. From studying the degradation of eosin $\mathrm{Y}$, it was found that the UV light photocatalytic performance varies in the following order: without catalyst $<$ naked $\mathrm{Fe}_{3} \mathrm{O}_{4}$ nanoparticles $<\mathrm{Ag-}$ $\mathrm{Fe}_{3} \mathrm{O}_{4}$ nanoparticles.

Figure 10 represents the mechanism for the role of $\mathrm{Ag}$ coating in $\mathrm{Fe}_{3} \mathrm{O}_{4}$ nanoparticles. During the photocatalytic reaction, there will be promotion of an electron from the valence band to the conduction band; thus electron-hole $\left(\mathrm{e}^{-} / \mathrm{h}^{+}\right)$pairs will form. The electron in the conduction 


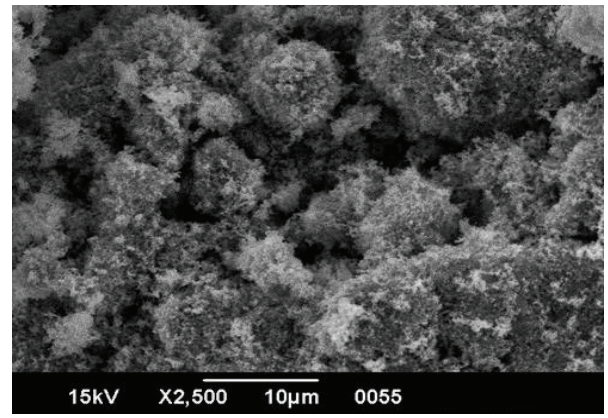

(a)

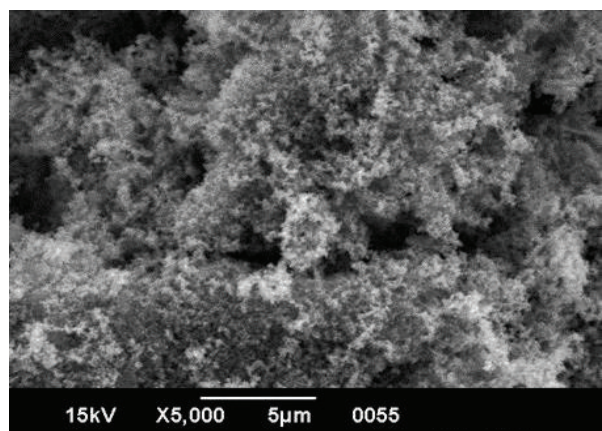

(c)

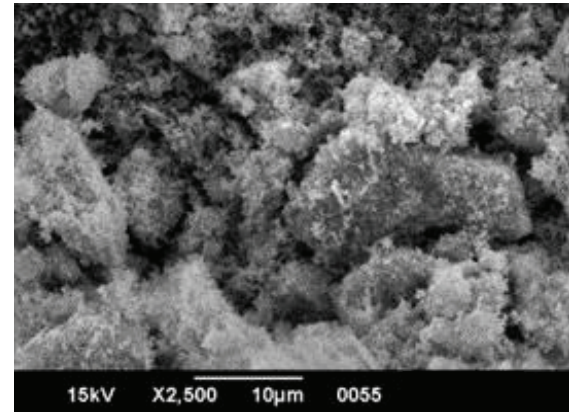

(b)

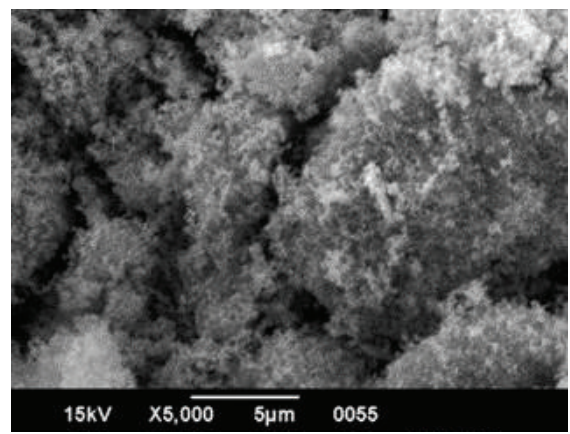

(d)

FIgURE 4: SEM micrographs of $\mathrm{Fe}_{3} \mathrm{O}_{4}$ nanoparticles ((a), (c)) and Ag-doped $\mathrm{Fe}_{3} \mathrm{O}_{4}$ nanoparticles ((b), (d)) at different magnifications.

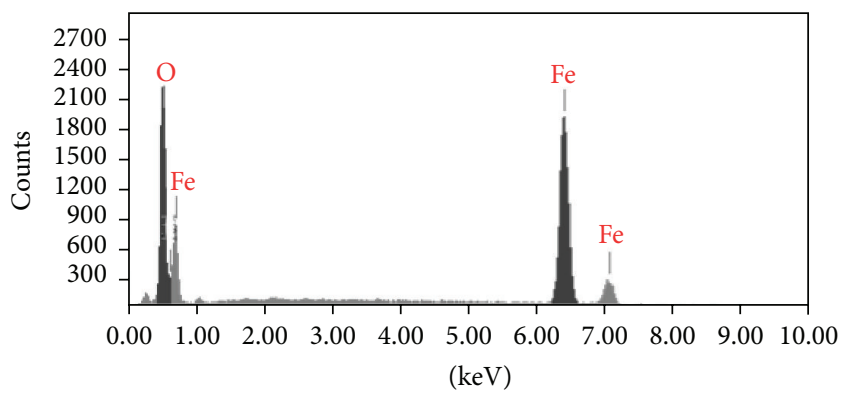

(a)

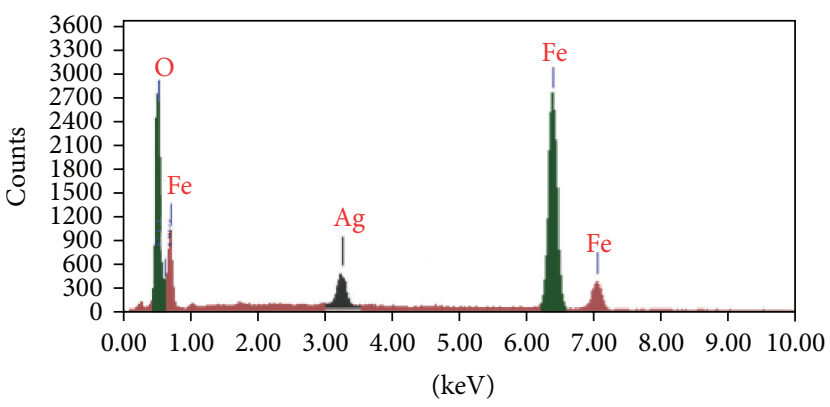

(b)

Figure 5: EDAX of (a) $\mathrm{Fe}_{3} \mathrm{O}_{4}$ nanoparticles and (b) Ag-doped $\mathrm{Fe}_{3} \mathrm{O}_{4}$ nanoparticles.

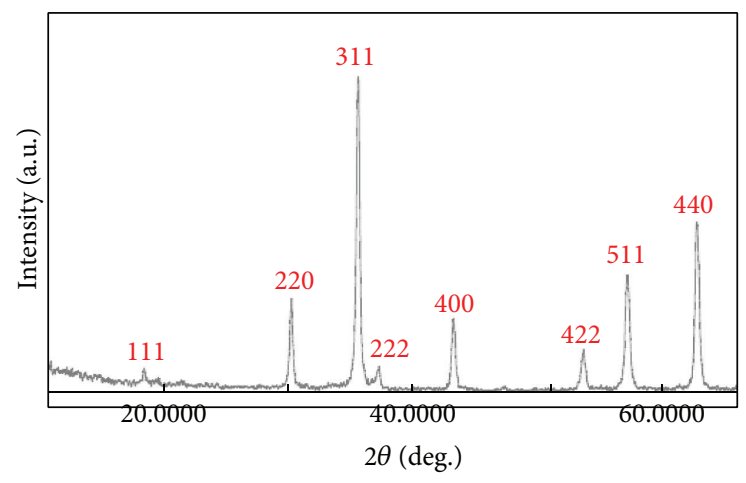

FiguRE 6: XRD pattern of $\mathrm{Fe}_{3} \mathrm{O}_{4}$ nanoparticles. 


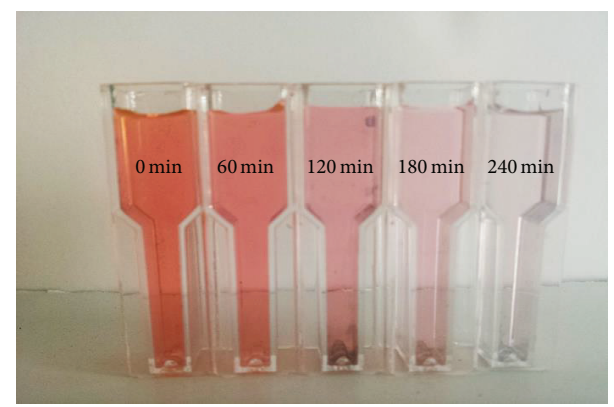

Figure 7: Photographs of eosin Y after treatment with the synthesised $\mathrm{Ag}-\mathrm{Fe}_{3} \mathrm{O}_{4}$ powder at different time intervals; the colour of eosin $\mathrm{Y}$ solution faded, indicating degradation of the dye.

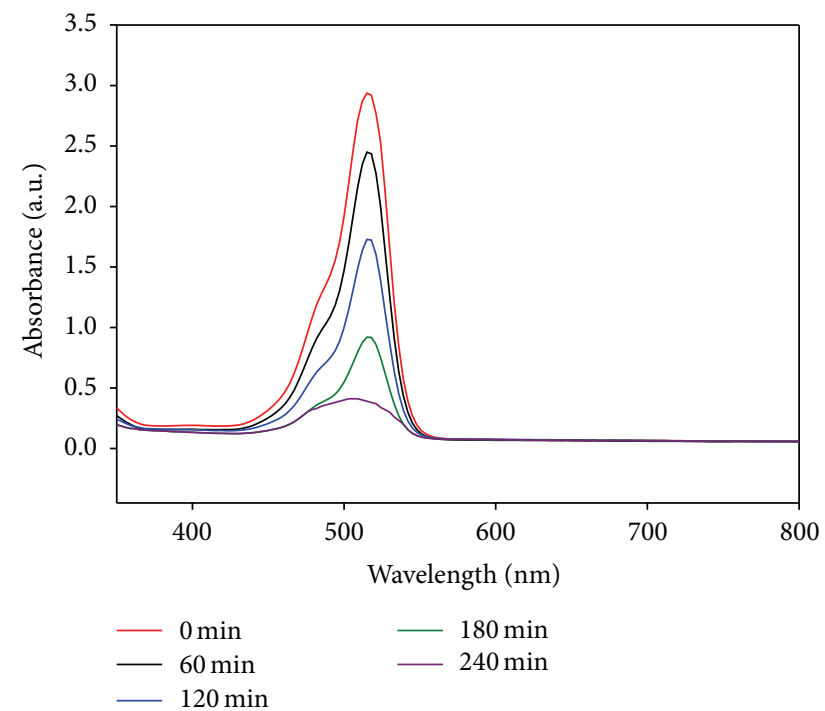

FIGURE 8: UV-Vis absorption spectra of eosin Y during the course of reaction with the synthesised Ag-MNP powder at different time intervals under ultraviolet light irradiation at room temperature.

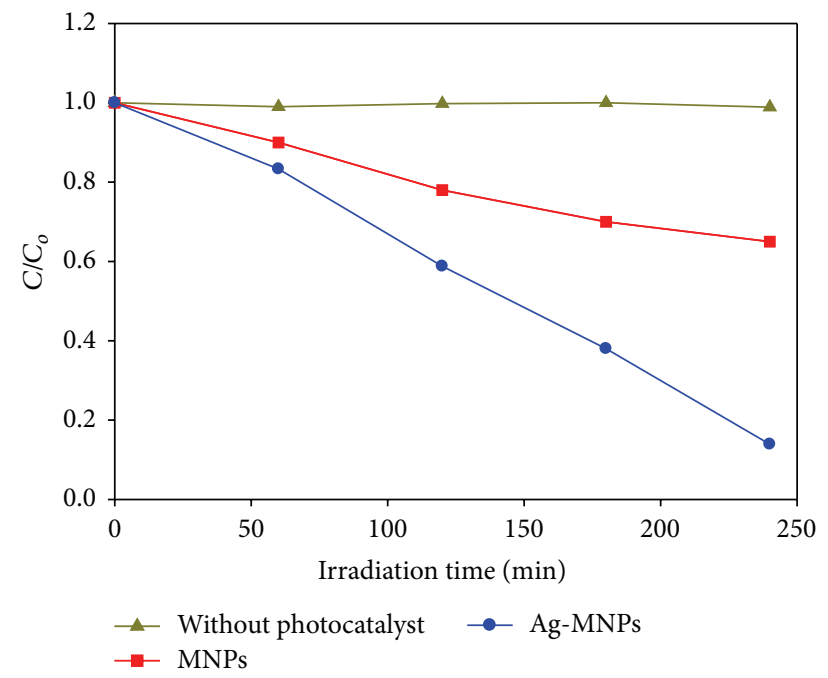

FIgURE 9: Photodegradation of eosin $\mathrm{Y}$ as a function of irradiation time in the absence and presence of MNPs or Ag-MNPs. band is removed by reaction with oxygen dissolved in water while the hole in the valence band can react with water or $\mathrm{OH}^{-}$that are absorbed on the surface of the silver-doped MNPs in order to give hydroxyl radical $\left({ }^{\circ} \mathrm{OH}\right)$, which is utilised as a powerful oxidizing agent in order to convert organic pollutants into $\mathrm{CO}_{2}, \mathrm{H}_{2} \mathrm{O}$, and less toxic by-products of low molecular weight [73]. The better photocatalytic activity shown by $\mathrm{Ag}-\mathrm{Fe}_{3} \mathrm{O}_{4}$ nanoparticles over naked $\mathrm{Fe}_{3} \mathrm{O}_{4}$ nanoparticles can be explained on the basis of silver being acceptor impurity in doping of $\mathrm{Fe}_{3} \mathrm{O}_{4}$. Ag acts as an electron trap and prevents the electron hole recombination that is an important factor in determining the photocatalytic activity $[72,74]$.

3.3.2. Kinetic Analysis. The rate of reaction in the photodegradation experiment was calculated using pseudo-firstorder kinetics: $\operatorname{In}\left(C_{o} / C\right)=k t$, where $C_{o}$ and $C$ are the absorption measured at different illumination times, $k$ is the reaction rate, and $t$ is the reaction time during the decomposition of eosin Y [75-79]. The reaction rate $(k)$ for the photodecomposition of eosin $\mathrm{Y}$ was calculated by drawing a graph between $\operatorname{In}\left(C_{o} / C\right)$ and $t$. Figure 11 presents the relationship between $\operatorname{In}\left(C_{o} / C\right)$ and $t$ as a function of irradiation time in the presence of $\mathrm{Ag}-\mathrm{Fe}_{3} \mathrm{O}_{4}$ nanoparticles. The figure shows that the photocatalytic degradation follows perfectly the pseudo-first-order kinetics, and the fairness of the fit is indicated by the linear regression value, $R^{2}=0.9938$.

3.3.3. Reuse of the Photocatalyst. The reuse and the stability of $\mathrm{Ag}-\mathrm{Fe}_{3} \mathrm{O}_{4}$ nanoparticles were studied in order to see the cost-effectiveness of the method. This was performed in a very simple way. After the degradation of eosin $\mathrm{Y}$, the Ag$\mathrm{Fe}_{3} \mathrm{O}_{4}$ nanoparticles were separated easily from the solution using a magnet, while the supernatant was decanted. Then, the magnetic nanoparticles were washed with distilled water and reused for degradation with a fresh lot of eosin $\mathrm{Y}$ solution. As can be seen in Figure 12, after using the Ag$\mathrm{Fe}_{3} \mathrm{O}_{4}$ nanoparticles for three times, the photodegradation of eosin $\mathrm{Y}$ did not show any significant loss of activity. These results confirmed that the $\mathrm{Ag}-\mathrm{Fe}_{3} \mathrm{O}_{4}$ nanoparticles are not photocorroded during photocatalytic oxidation of the dye.

\section{Conclusions}

Photocatalysis has been ascertained to be a promising method for the removal of harmful dyes from industrial wastewater. In this study, the fabrication of MNPs with coating of Ag was successfully performed. The morphology of the fabricated magnetic nanoparticles before and after the modification with silver was characterised using TEM analysis to conduct the size investigations; SEM analysis was carried out for the surface morphology analysis and EDAX for the compositional analysis. The crystalline structures of the nanoparticles were identified with XRD, which showed the XRD patterns of the $\mathrm{Fe}_{3} \mathrm{O}_{4}$. The experimental results showed that the Ag-MNPs were more effective in enhancing the photocatalytic degradation of eosin Y over naked MNPs. Moreover, the fabricated materials were easily recovered by using an external magnet after the treatment of eosin Y. It is 


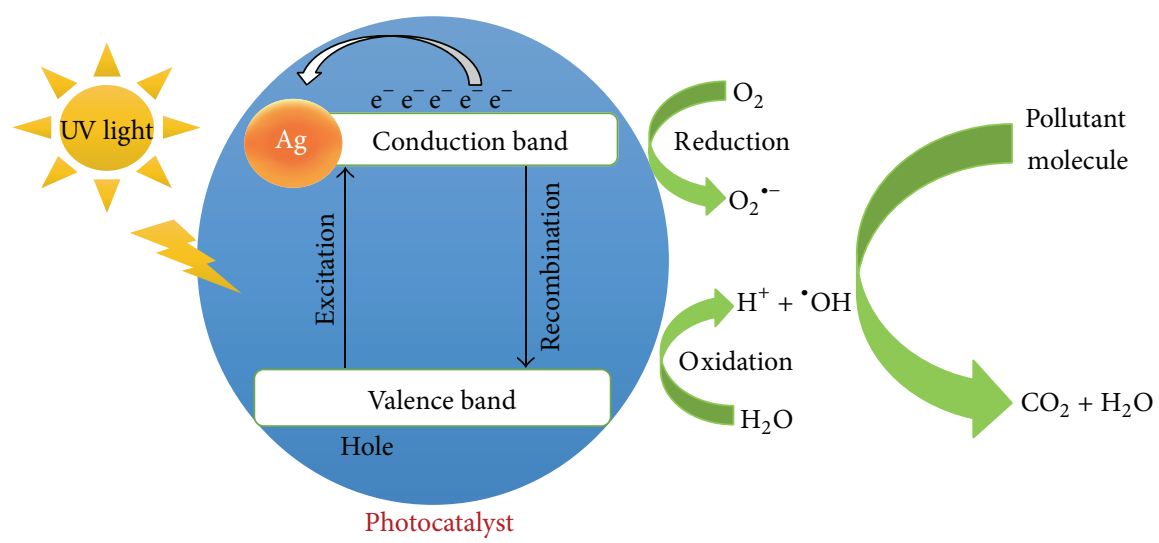

FIGURE 10: Schematic diagram of the reaction mechanism involved in photocatalytic activity of Ag-MNPs nanoparticles.

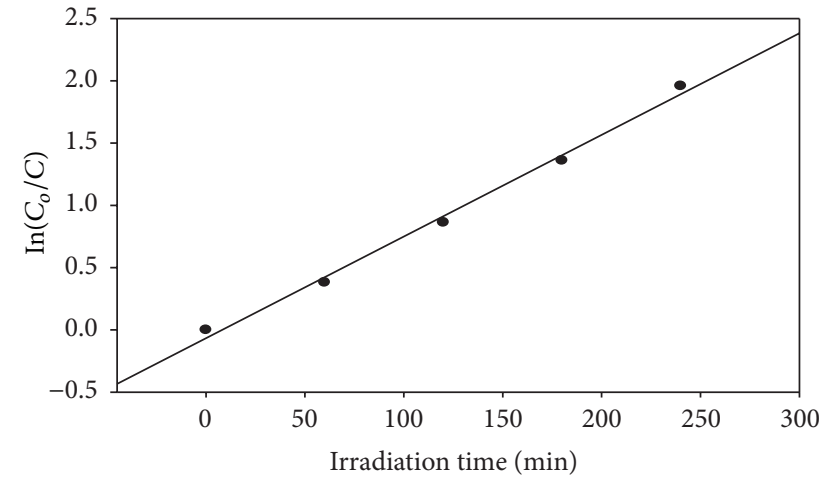

FIgURE 11: Plot of $\operatorname{In}\left(C_{o} / C\right)$ versus irradiation time.

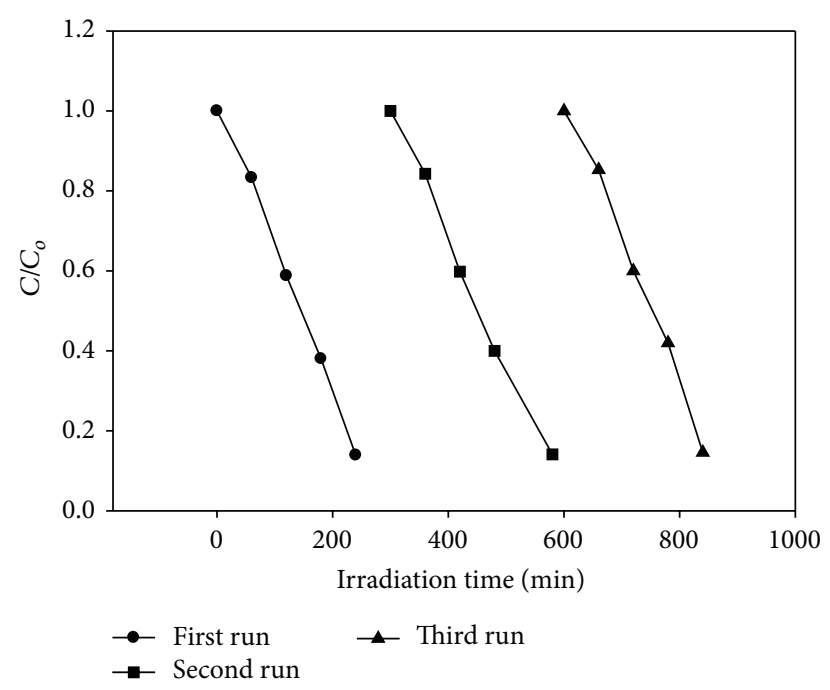

Figure 12: Recycled photocatalytic degradation of eosin Y.

suggested that the UV/Ag- $\mathrm{Fe}_{3} \mathrm{O}_{4}$ system could be used as a useful technique for the removal of harmful dyes from industrial wastewater. Work is currently investigating different azo dyes using the fabricated Ag-MNPs nanoparticles.

\section{Conflict of Interests}

The author declares that there is no conflict of interests regarding the publication of this paper.

\section{Acknowledgment}

This work was funded by King Abdulaziz City for Science and Technology (KACST).

\section{References}

[1] E. Gurr, Synthetic Dyes in Biology, Medicine and Chemistry, Elsevier, 2012.

[2] Shahid-ul-Islam and F. Mohammad, "High-energy radiation induced sustainable coloration and functional finishing of textile materials," Industrial \& Engineering Chemistry Research, vol. 54, no. 15, pp. 3727-3745, 2015.

[3] C. Namasivayam and D. Kavitha, "Removal of Congo Red from water by adsorption onto activated carbon prepared from coir pith, an agricultural solid waste," Dyes and Pigments, vol. 54, no. 1, pp. 47-58, 2002.

[4] R. Gong, Y. Sun, J. Chen, H. Liu, and C. Yang, "Effect of chemical modification on dye adsorption capacity of peanut hull," Dyes and Pigments, vol. 67, no. 3, pp. 175-181, 2005.

[5] M. B. Hasan, Adsorption of reactive azo dyes on chitosan/oil palm ash composite adsorbent: batch and continuous studies [M.S. thesis], Universiti Sains Malaysia, George Town, Malaysia, 2008.

[6] I. A. W. Tan, A. L. Ahmad, and B. H. Hameed, "Preparation of activated carbon from coconut husk: optimization study on removal of 2,4,6-trichlorophenol using response surface methodology," Journal of Hazardous Materials, vol. 153, no. 1-2, pp. 709-717, 2008.

[7] I. A. W. Tan, A. L. Ahmad, and B. H. Hameed, "Adsorption of basic dye on high-surface-area activated carbon prepared from coconut husk: equilibrium, kinetic and thermodynamic studies," Journal of Hazardous Materials, vol. 154, no. 1-3, pp. 337-346, 2008.

[8] F. Shakeel, N. Haq, F. K. Alanazi, and I. A. Alsarra, "BoxBehnken statistical design for removal of methylene blue from aqueous solution using sodium dodecyl sulfate selfmicroemulsifying systems," Industrial \& Engineering Chemistry Research, vol. 53, no. 3, pp. 1179-1188, 2014. 
[9] H. Kim, S. Lee, S. Ryu, and H. T. Choi, "Decolorization of remazol brilliant blue $\mathrm{R}$ by a purified laccase of Polyporus brumalis," Applied Biochemistry and Biotechnology, vol. 166, no. 1, pp. 159-164, 2012.

[10] A. K. Verma, R. R. Dash, and P. Bhunia, "A review on chemical coagulation/flocculation technologies for removal of colour from textile wastewaters," Journal of Environmental Management, vol. 93, no. 1, pp. 154-168, 2012.

[11] Y. Patel and A. Gupte, "Biological treatment of textile dyes by agar-agar immobilized consortium in a packed bed reactor," Water Environment Research, vol. 87, no. 3, pp. 242-251, 2015.

[12] G. Crini, "Non-conventional low-cost adsorbents for dye removal: a review," Bioresource Technology, vol. 97, no. 9, pp. 1061-1085, 2006.

[13] S. Mondal, "Methods of dye removal from dye house effluentan overview," Environmental Engineering Science, vol. 25, no. 3, pp. 383-396, 2008.

[14] S. D. Khattri and M. K. Singh, "Removal of malachite green from dye wastewater using neem sawdust by adsorption," Journal of Hazardous Materials, vol. 167, no. 1-3, pp. 1089-1094, 2009.

[15] A. Srinivasan and T. Viraraghavan, "Decolorization of dye wastewaters by biosorbents: a review," Journal of Environmental Management, vol. 91, no. 10, pp. 1915-1929, 2010.

[16] A. Mittal, V. Thakur, J. Mittal, and H. Vardhan, "Process development for the removal of hazardous anionic azo dye Congo red from wastewater by using hen feather as potential adsorbent," Desalination and Water Treatment, vol. 52, no. 1-3, pp. 227-237, 2014.

[17] U. Rott, "Multiple use of water in industry-the textile industry case," Journal of Environmental Science and Health Part A, vol. 38, no. 8, pp. 1629-1639, 2003.

[18] Z. Houshyar, A. B. Khoshfetrat, and E. Fatehifar, "Influence of ozonation process on characteristics of pre-alkalized tannery effluents," Chemical Engineering Journal, vol. 191, pp. 59-65, 2012.

[19] D. Ghernaout, C. Benblidia, and F. Khemici, "Microalgae removal from Ghrib Dam (Ain Defla, Algeria) water by electroflotation using stainless steel electrodes," Desalination and Water Treatment, vol. 54, no. 12, pp. 3328-3337, 2015.

[20] A. Aouni, C. Fersi, M. Ben Sik Ali, and M. Dhahbi, "Treatment of textile wastewater by a hybrid electrocoagulation/nanofiltration process," Journal of Hazardous Materials, vol. 168, no. 2-3, pp. 868-874, 2009.

[21] A. Maljaei, M. Arami, and N. M. Mahmoodi, "Decolorization and aromatic ring degradation of colored textile wastewater using indirect electrochemical oxidation method," Desalination, vol. 249, no. 3, pp. 1074-1078, 2009.

[22] M. Rafatullah, O. Sulaiman, R. Hashim, and A. Ahmad, "Adsorption of methylene blue on low-cost adsorbents: a review," Journal of Hazardous Materials, vol. 177, no. 1, pp. 7080, 2010.

[23] P. K. Malik, "Dye removal from wastewater using activated carbon developed from sawdust: adsorption equilibrium and kinetics," Journal of Hazardous Materials, vol. 113, no. 1-3, pp. 81-88, 2004.

[24] M. K. Purkait, A. Maiti, S. DasGupta, and S. De, "Removal of congo red using activated carbon and its regeneration," Journal of Hazardous Materials, vol. 145, no. 1-2, pp. 287-295, 2007.

[25] V. K. Gupta, B. Gupta, A. Rastogi, S. Agarwal, and A. Nayak, "A comparative investigation on adsorption performances of mesoporous activated carbon prepared from waste rubber tire and activated carbon for a hazardous azo dye-acid Blue 113," Journal of Hazardous Materials, vol. 186, no. 1, pp. 891-901, 2011.

[26] A. A. Ahmad, A. Idris, and B. H. Hameed, "Modeling of disperse dye adsorption onto bamboo-based activated carbon in fixedbed column," Desalination and Water Treatment, vol. 52, no. 1-3, pp. 248-256, 2014.

[27] W. Chu, "Dye removal from textile dye wastewater using recycled alum sludge," Water Research, vol. 35, no. 13, pp. 31473152, 2001.

[28] T. Robinson, G. McMullan, R. Marchant, and P. Nigam, "Remediation of dyes in textile effluent: a critical review on current treatment technologies with a proposed alternative," Bioresource Technology, vol. 77, no. 3, pp. 247-255, 2001.

[29] V. K. Gupta, I. Ali, Suhas, and D. Mohan, "Equilibrium uptake and sorption dynamics for the removal of a basic dye (basic red) using low-cost adsorbents," Journal of Colloid and Interface Science, vol. 265, no. 2, pp. 257-264, 2003.

[30] X. Cai, Y. Wang, B. Han et al., "Hydrothermal growth of $\mathrm{ZnO}$ nanorods on $\mathrm{Zn}$ substrates and their application in degradation of azo dyes under ambient conditions," CrystEngComm, vol. 16, no. 33, pp. 7761-7770, 2014.

[31] Y. Zhang and C. Erkey, "Preparation of supported metallic nanoparticles using supercritical fluids: a review," The Journal of Supercritical Fluids, vol. 38, no. 2, pp. 252-267, 2006.

[32] Y. Li and G. A. Somorjai, "Nanoscale advances in catalysis and energy applications," Nano Letters, vol. 10, no. 7, pp. 2289-2295, 2010.

[33] E. Alzahrani and K. Welham, "Optimization preparation of the biosynthesis of silver nanoparticles using watermelon and study of itsantibacterial activity," International Journal of Basic and Applied Sciences, vol. 3, no. 4, pp. 392-400, 2014.

[34] E. Alzahrani, "Eco-friendly production of silver nanoparticles from peel of tangerine for degradation of dye," World Journal of Nano Science and Engineering, vol. 5, no. 1, pp. 10-16, 2015.

[35] M. Wierucka and M. Biziuk, "Application of magnetic nanoparticles for magnetic solid-phase extraction in preparing biological, environmental and food samples," TrAC-Trends in Analytical Chemistry, vol. 59, pp. 50-58, 2014.

[36] M. M. El-Hammadi and J. L. Arias, "Iron oxide-based multifunctional nanoparticulate systems for biomedical applications: a patent review (2008-present)," Expert Opinion on Therapeutic Patents, vol. 25, no. 6, pp. 691-709, 2015.

[37] S. Majidi, F. Z. Sehrig, M. Samiei et al., "Magnetic nanoparticles: applications in gene delivery and gene therapy," Artificial Cells, Nanomedicine, and Biotechnology, 2015.

[38] C. Sun, J. S. H. Lee, and M. Zhang, "Magnetic nanoparticles in MR imaging and drug delivery," Advanced Drug Delivery Reviews, vol. 60, no. 11, pp. 1252-1265, 2008.

[39] V. I. Shubayev, T. R. Pisanic II, and S. Jin, "Magnetic nanoparticles for theragnostics," Advanced Drug Delivery Reviews, vol. 61, no. 6, pp. 467-477, 2009.

[40] E. Alzahrani, "Fabrication and characterisation of chitosanmagnetic nanoparticles and its application for protein extraction," International Journal of Advanced Scientific and Technical Research, vol. 4, no. 4, pp. 755-766, 2014.

[41] E. Alzahrani, A. Sharfalddin, and M. Alamodi, "Microwavehydrothermal synthesis of ferric oxide doped with cobalt," Advances in Nanoparticles, vol. 4, no. 2, pp. 53-60, 2015.

[42] C. Yang, J. Xing, Y. Guan, J. Liu, and H. Liu, "Synthesis and characterization of superparamagnetic iron nanocomposites by hydrazine reduction," Journal of Alloys and Compounds, vol. 385, no. 1-2, pp. 283-287, 2004. 
[43] W. Yantasee, C. L. Warner, T. Sangvanich et al., "Removal of heavy metals from aqueous systems with thiol functionalized superparamagnetic nanoparticles," Environmental Science \& Technology, vol. 41, no. 14, pp. 5114-5119, 2007.

[44] Y. Cedeño-Mattei, O. Perales-Perez, M. S. Tomar, F. Roman, P. M. Voyles, and W. G. Stratton, "Tuning of magnetic properties in cobalt ferrite nanocrystals," Journal of Applied Physics, vol. 103, no. 7, pp. 1-3, 2008.

[45] D. Wang and D. Astruc, "Fast-growing field of magnetically recyclable nanocatalysts," Chemical Reviews, vol. 114, no. 14, pp. 6949-6985, 2014.

[46] K. Woo, J. Hong, S. Choi et al., "Easy synthesis and magnetic properties of iron oxide nanoparticles," Chemistry of Materials, vol. 16, no. 14, pp. 2814-2818, 2004.

[47] A.-H. Lu, E. L. Salabas, and F. Schüth, "Magnetic nanoparticles: synthesis, protection, functionalization, and application," Angewandte Chemie, vol. 46, no. 8, pp. 1222-1244, 2007.

[48] S. Laurent, D. Forge, M. Port et al., "Magnetic iron oxide nanoparticles: synthesis, stabilization, vectorization, physicochemical characterizations, and biological applications," Chemical Reviews, vol. 108, no. 6, pp. 2064-2110, 2008.

[49] A. S. Teja and P.-Y. Koh, "Synthesis, properties, and applications of magnetic iron oxide nanoparticles," Progress in Crystal Growth and Characterization of Materials, vol. 55, no. 1-2, pp. 22-45, 2009.

[50] M. H. Ramezanzadeh, M. Seifi, H. Hekmatara, Z. Zarnegar, and M. H. Loghmani, "Synthesis and survey magnetic properties of $\mathrm{Fe}_{2} \mathrm{O}_{3}$ nanoparticles coated with different surfactant," Synthesis and Reactivity in Inorganic, Metal-Organic and Nano-Metal Chemistry, vol. 45, no. 3, pp. 392-396, 2014.

[51] W. Wu, Q. He, and C. Jiang, "Magnetic iron oxide nanoparticles: synthesis and surface functionalization strategies," Nanoscale Research Letters, vol. 3, no. 11, pp. 397-415, 2008.

[52] S. Mallakpour and M. Madani, "A review of current coupling agents for modification of metal oxide nanoparticles," Progress in Organic Coatings, vol. 86, pp. 194-207, 2015.

[53] A. Sclafani and J.-M. Herrmann, "Influence of metallic silver and of platinum-silver bimetallic deposits on the photocatalytic activity of titania (anatase and rutile) in organic and aqueous media," Journal of Photochemistry and Photobiology A: Chemistry, vol. 113, no. 2, pp. 181-188, 1998.

[54] M. J. Kale, T. Avanesian, and P. Christopher, "Direct photocatalysis by plasmonic nanostructures," ACS Catalysis, vol. 4, no. 1, pp. 116-128, 2014.

[55] W. Tan and M. A. Bakar, "The effect of additives on the size of $\mathrm{Fe}_{3} \mathrm{O}_{4}$ particles," Journal of Physical Science, vol. 17, no. 2, pp. 37-50, 2006.

[56] S. K. Das, M. K. Bhunia, and A. Bhaumik, "Self-assembled $\mathrm{TiO}_{2}$ nanoparticles: mesoporosity, optical and catalytic properties," Dalton Transactions, vol. 39, no. 18, pp. 4382-4390, 2010.

[57] M. Salehi, H. Hashemipour, and M. Mirzaee, "Experimental study of influencing factors and kinetics in catalytic removal of methylene blue with $\mathrm{TiO}_{2}$ nanopowder," American Journal of Environmental Engineering, vol. 2, no. 1, pp. 1-7, 2012.

[58] S. Alahiane, S. Qourzal, M. El Ouardi, A. Abaamrane, and A. Assabbane, "Factors influencing the photocatalytic degradation of reactive yellow 145 by $\mathrm{TiO}_{2}$-coated non-woven fibers," American Journal of Analytical Chemistry, vol. 5, no. 8, pp. 445-454, 2014.

[59] J. S. Beveridge, J. R. Stephens, and M. E. Williams, "The use of magnetic nanoparticles in analytical chemistry," Annual Review of Analytical Chemistry, vol. 4, pp. 251-273, 2011.
[60] F. Ridi, M. Bonini, and P. Baglioni, "Magneto-responsive nanocomposites: preparation and integration of magnetic nanoparticles into films, capsules, and gels," Advances in Colloid and Interface Science, vol. 207, no. 1, pp. 3-13, 2014.

[61] N. Mizutani, T. Iwasaki, S. Watano, T. Yanagida, H. Tanaka, and T. Kawai, "Effect of ferrous/ferric ions molar ratio on reaction mechanism for hydrothermal synthesis of magnetite nanoparticles," Bulletin of Materials Science, vol. 31, no. 5, pp. 713-717, 2008.

[62] K. Petcharoen and A. Sirivat, "Synthesis and characterization of magnetite nanoparticles via the chemical co-precipitation method," Materials Science and Engineering B: Solid-State Materials for Advanced Technology, vol. 177, no. 5, pp. 421-427, 2012.

[63] B. Zheng, M. Zhang, D. Xiao, Y. Jin, and M. M. F. Choi, "Fast microwave synthesis of $\mathrm{Fe}_{3} \mathrm{O}_{4}$ and $\mathrm{Fe}_{3} \mathrm{O}_{4} / \mathrm{Ag}$ magnetic nanoparticles using $\mathrm{Fe}^{2+}$ as precursor," Inorganic Materials, vol. 46, no. 10, pp. 1106-1111, 2010.

[64] N. Mizutani, T. Iwasaki, and S. Watano, "Response surface methodology study on magnetite nanoparticle formation under hydrothermal conditions," Nanomaterials and Nanotechnology, vol. 5, no. 13, pp. 1-7, 2015.

[65] P. Xu, G. M. Zeng, D. L. Huang et al., "Use of iron oxide nanomaterials in wastewater treatment: a review," Science of the Total Environment, vol. 424, pp. 1-10, 2012.

[66] S. Suwanboon, P. Amornpitoksuk, A. Sukolrat, and N. Muensit, "Optical and photocatalytic properties of La-doped $\mathrm{ZnO}$ nanoparticles prepared via precipitation and mechanical milling method," Ceramics International, vol. 39, no. 3, pp. 2811-2819, 2013.

[67] R. Abazari, S. Sanati, and L. A. Saghatforoush, "Non-aggregated divanadium pentoxide nanoparticles: a one-step facile synthesis. Morphological, structural, compositional, optical properties and photocatalytic activities," Chemical Engineering Journal, vol. 236, pp. 82-90, 2014.

[68] L. Reimer, Transmission Electron Microscopy: Physics of Image Formation and Microanalysis, Springer, 2013.

[69] J. Olson, S. Dominguez-Medina, A. Hoggard, L.-Y. Wang, W.S. Chang, and S. Link, "Optical characterization of single plasmonic nanoparticles," Chemical Society Reviews, vol. 44, no. 1, pp. 40-57, 2015.

[70] B. Fang, G. Wang, W. Zhang, M. Li, and X. Kan, "Fabrication of $\mathrm{Fe}_{3} \mathrm{O}_{4}$ nanoparticles modified electrode and its application for voltammetric sensing of dopamine," Electroanalysis, vol. 17, no. 9, pp. 744-748, 2005.

[71] S. F. Chin, K. S. Iyer, and C. L. Raston, "Facile and green approach to fabricate gold and silver coated superparamagnetic nanoparticles," Crystal Growth and Design, vol. 9, no. 6, pp. 2685-2689, 2009.

[72] I. S. Lydia, J. P. Merlin, V. V. Dhayabaran, and N. Radhika, "Photodegradation of methylred using Ag-doped Fe3O4 nanoparticles," International Journal of Chemical and Environmental Engineering, vol. 3, no. 4, pp. 209-216, 2012.

[73] J.-M. Lee, M.-S. Kim, and B.-W. Kim, "Photodegradation of bisphenol-A with $\mathrm{TiO}_{2}$ immobilized on the glass tubes including the UV light lamps," Water Research, vol. 38, no. 16, pp. 3605-3613, 2004.

[74] R. Nainani, P. Thakur, and M. Chaskar, "Synthesis of silver doped $\mathrm{TiO}_{2}$ nanoparticles for the improved photocatalytic degradation of methyl orange," Journal of Materials Science and Engineering B, vol. 2, no. 1, pp. 52-58, 2012.

[75] A. M. Asiri, M. S. Al-Amoudi, T. A. Al-Talhi, and A. D. AlTalhi, "Photodegradation of Rhodamine 6G and phenol red 
by nanosized $\mathrm{TiO}_{2}$ under solar irradiation," Journal of Saudi Chemical Society, vol. 15, no. 2, pp. 121-128, 2011.

[76] V. K. Gupta, R. Jain, S. Agarwal, A. Nayak, and M. Shrivastava, "Photodegradation of hazardous dye quinoline yellow catalyzed by $\mathrm{TiO}_{2}$," Journal of Colloid and Interface Science, vol. 366, no. 1, pp. 135-140, 2012.

[77] R. V. Solomon, I. S. Lydia, J. P. Merlin, and P. Venuvanalingam, "Enhanced photocatalytic degradation of azo dyes using nano $\mathrm{Fe}_{3} \mathrm{O}_{4}$," Journal of the Iranian Chemical Society, vol. 9, no. 2, pp. 101-109, 2012.

[78] S. Thirumalairajan, K. Girija, V. R. Mastelaro, and N. Ponpandian, "Photocatalytic degradation of organic dyes under visible light irradiation by floral-like $\mathrm{LaFeO}_{3}$ nanostructures comprised of nanosheet petals," New Journal of Chemistry, vol. 38, no. 11, pp. 5480-5490, 2014.

[79] Y. Yao, Y. Cai, F. Lu, F. Wei, X. Wang, and S. Wang, "Magnetic recoverable $\mathrm{MnFe}_{2} \mathrm{O}_{4}$ and $\mathrm{MnFe}_{2} \mathrm{O}_{4}$-graphene hybrid as heterogeneous catalysts of peroxymonosulfate activation for efficient degradation of aqueous organic pollutants," Journal of Hazardous Materials, vol. 270, pp. 61-70, 2014. 

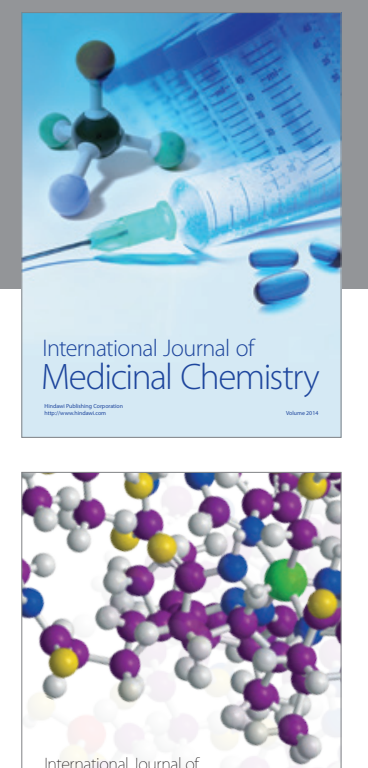

\section{Carbohydrate} Chemistry

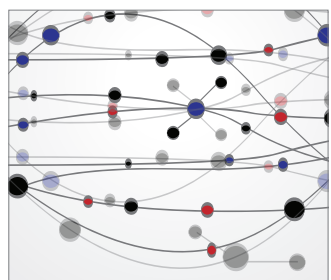

The Scientific World Journal
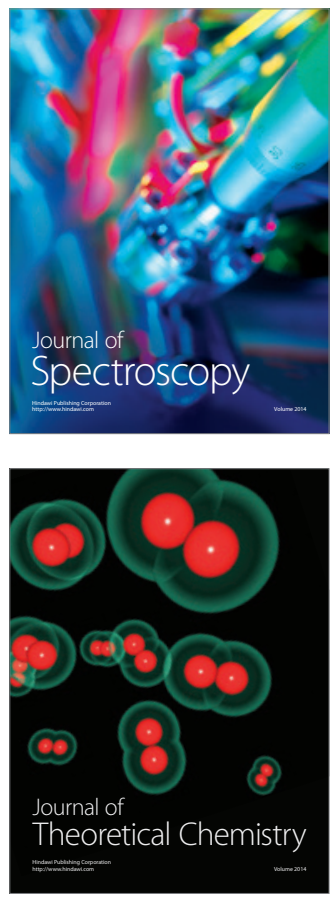
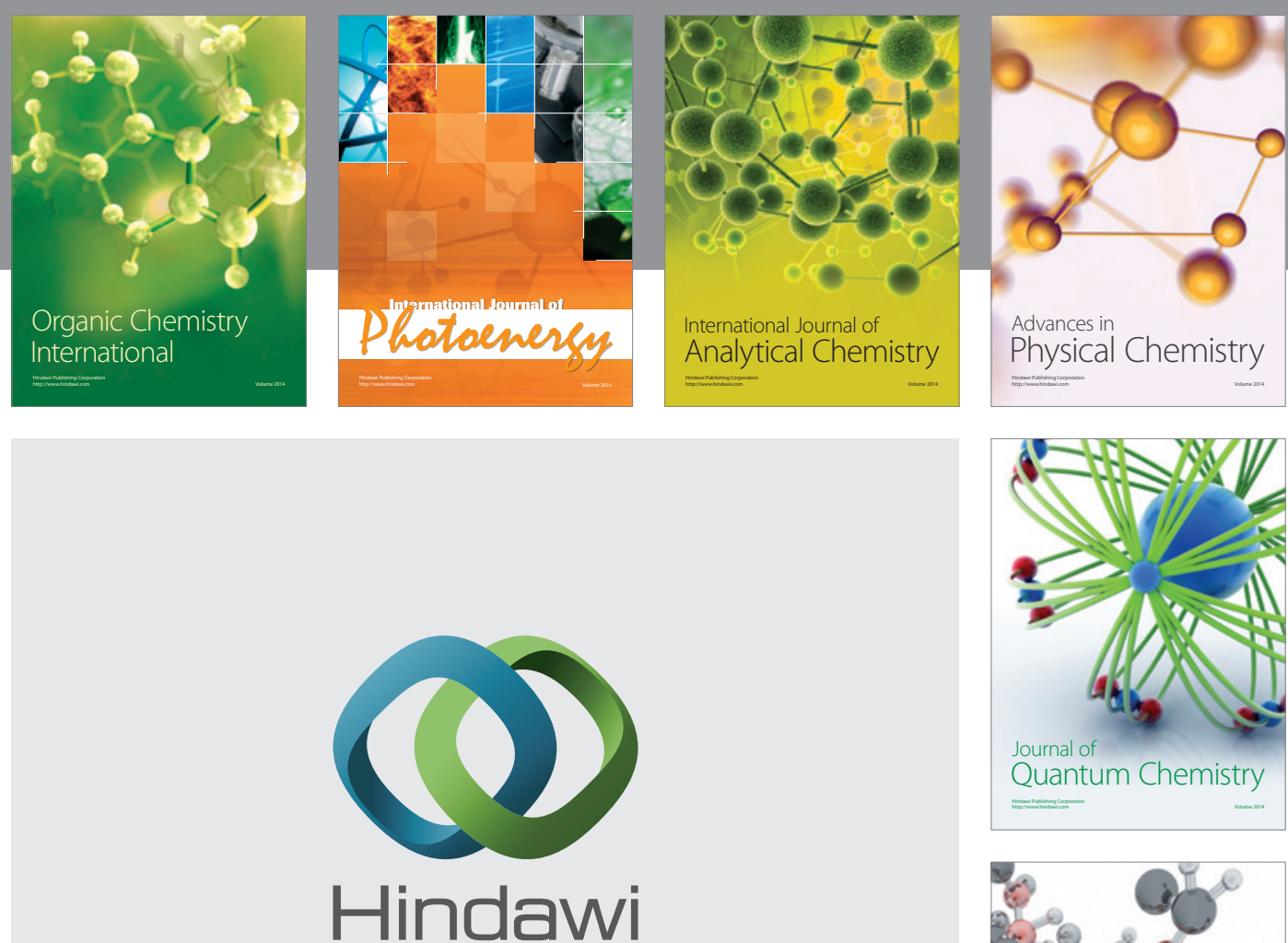

Submit your manuscripts at

http://www.hindawi.com

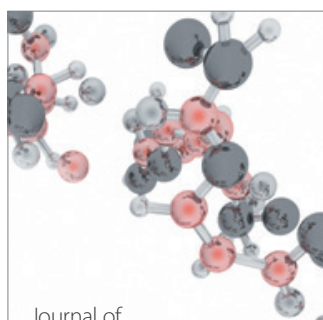

Analytical Methods

in Chemistry

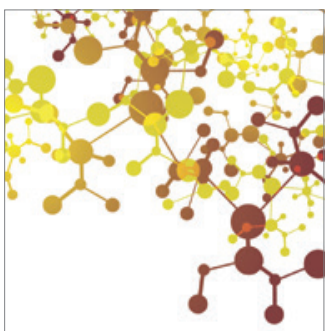

Journal of

Applied Chemistry

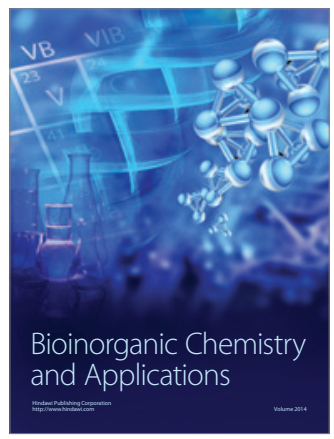

Inorganic Chemistry
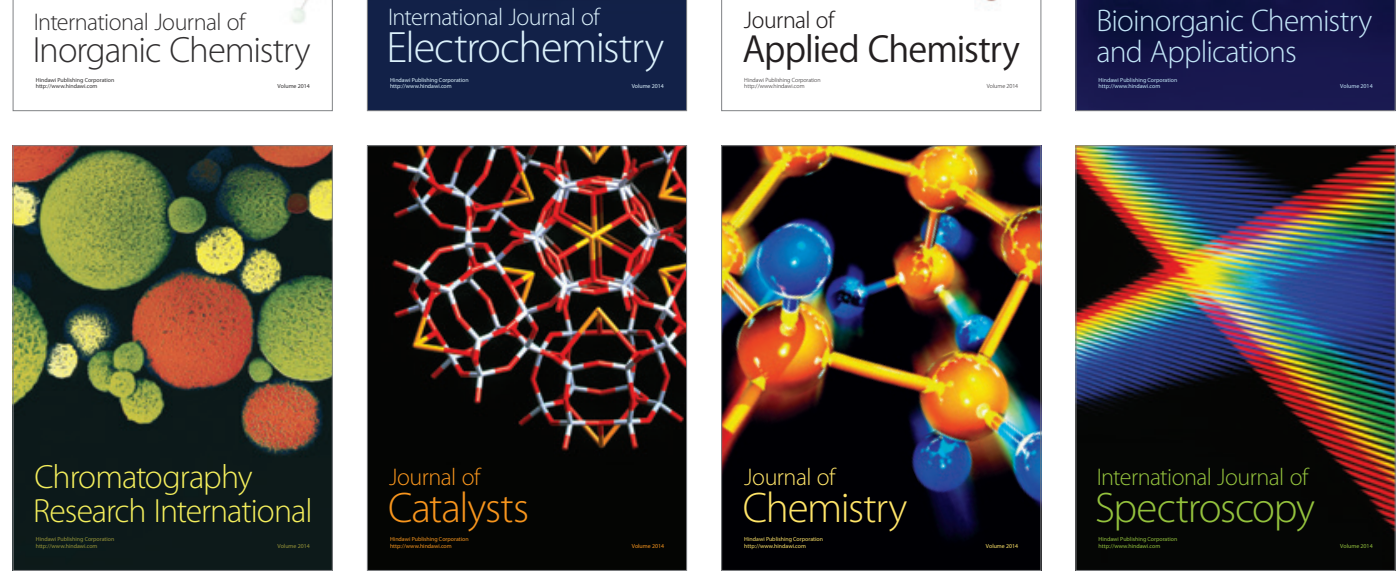